\title{
Enamel Erosion by Some Soft Drinks and Orange Juices Relative to Their pH, Buffering Effect and Contents of Calcium Phosphate
}

\author{
M.J. Larsen B. Nyvad \\ Department of Operative Dentistry and Endodontics, Royal Dental College, Faculty of Health Sciences, \\ Aarhus C, Denmark
}

\section{Key Words}

Buffering effect - Enamel dissolution - Erosion - Orange juice $\cdot \mathrm{pH} \cdot$ Soft drinks

\begin{abstract}
The capability of a soft drink or a juice to erode dental enamel depends not only on the $\mathrm{pH}$ of the drink, but also on its buffering effect. As the latter is the ability of the drink to resist a change of $\mathrm{pH}$ it may add to the effects of the actual $\mathrm{pH}$. The aim of the present study was to compare the $\mathrm{pH}$ and the buffering effect of various soft drinks with their erosive effects and the solubility of apatite. In 18 soft drinks, mineral waters and juices available on the Danish market, $\mathrm{pH}$ and the concentrations of calcium, phosphate and fluoride were determined. The buffering effect was determined by titration with $\mathrm{NaOH}$. Human teeth ( $n=54$ ) covered with nail varnish except for $3 \times 4-\mathrm{mm}$ windows were exposed to 1.5 liters of the drink for either 7 days or $24 \mathrm{~h}$ under constant agitation. The depth of the erosions was assessed in longitudinal sections. The depth was found to vary greatly from 3 $\mathrm{mm}$ eroded by the most acidic drinks and fresh orange juice to only slightly affected surfaces by most of the mineral waters. The dissolution of enamel increased logarithmically inversely with the $\mathrm{pH}$ of the drink and parallel with the solubility of enamel apatite. Orange juice, $\mathrm{pH} 4.0$, supplemented with $40 \mathrm{mmol} / \mathrm{l}$ calcium and $30 \mathrm{mmol} / \mathrm{l}$ phosphate did not erode the enamel as the
\end{abstract}

\section{KARGER}

Fax +4161306 1234

E-Mail karger@karger.ch

www.karger.com (c) 1999 S. Karger AG, Basel

0008-6568/99/0331-0081 \$15.00/0

Accessible online at: http://BioMedNet.com/karger calcium and phosphate saturated the drink with respect to apatite. Generally, the lower the $\mathrm{pH}$ the more $\mathrm{NaOH}$ was necessary to bring the $\mathrm{pH}$ to neutrality. In particular the buffering effect of the juice was high. For all drinks, no effect of their low fluoride concentrations was observed.

Over the last decades, the prevalence of erosion seems to have increased [Nunn, 1996], presumably due to an increasing consumption of soft drinks and fruit juices. The factors known to cause erosion include all kinds of acidic foods with a low concentration of calcium and phosphate [Meurman et al., 1987; Lussi et al., 1993; Zero, 1996]. The erosive agents are characterized as being highly undersaturated with respect to both hydroxyapatite and fluorapatite [Larsen, 1975; Meurman and ten Cate, 1996] so that enamel apatite dissolves without any mutual formation of surface fluorhydroxyapatite [Larsen, 1973].

When enamel dissolves in vivo the dissolution causes either of two distinctly different types of lesions, a caries lesion or erosion. By definition, a caries lesion is caused by acids formed by bacterial degradation of sugars, whilst erosion is defined as chemical dissolution caused by acids of any other origin [Imfeld, 1996]. Due to the nature and origin of the acid, the caries lesion is localized under plaque whilst erosion appears widespread on exposed surfaces. The two lesions are histologically clearly different, the caries le- 


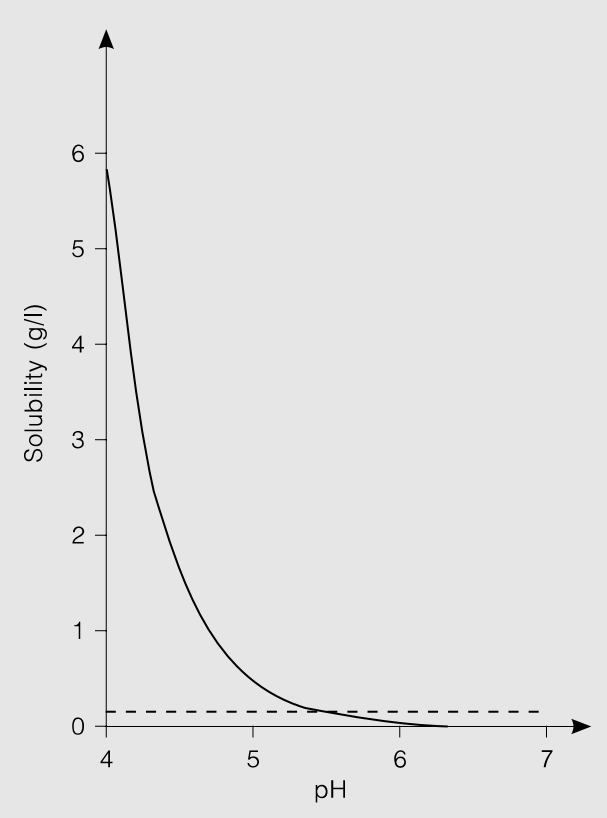

Fig. 1. Apatite solubility as a function of $\mathrm{pH}$ in the range 7-4 as calculated by a previously published computer program [Larsen, 1986]. The conditions were: a $\mathrm{Ca} / \mathrm{P}$ ratio of $5 / 3$, a $\mathrm{pK}_{\mathrm{HAp}}$ of 58.5 [McDowell et al., 1977] and that enamel contains $38 \%$ calcium. For comparison, $\mathrm{pH}$ in plaque after a sucrose rinse considered to be cariogenic usually ranges above $\mathrm{pH} 4.5$. The dotted horizontal line that intersects the curve around the critical $\mathrm{pH}$ of 5.5 indicates calcium and phosphate levels in saliva.

sion being a gradual demineralization of subsurface enamel and dentin with the outer 20 - to $50-\mu \mathrm{m}$-thick surface layer preserved more or less intact, in contrast to the erosion in which the dental mineral is dissolved layer by layer leaving the subsurface enamel almost unaltered. A softening of the eroded enamel surface indicative of a slight demineralization of the very surface enamel was observed by Meurman et al. [1990].

In erosion the amount of mineral dissolved from enamel depends on a number of conditions: $\mathrm{pH}$, the buffering effect or the concentration of acids and the length of the exposure time. Finally, the presence of suitable concentrations of calcium, phosphate and fluoride in the drink may counteract the dissolution.

Figures 1 and 2 demonstrate that the solubility of apatite (defined as the amount of apatite that can exist dissolved at equilibrium at the actual $\mathrm{pH}$ ) increases logarithmically with a drop in $\mathrm{pH}$, the increase in solubility being largest at low $\mathrm{pH}$. Although the solubility of apatite is considerable around $\mathrm{pH} 4$ it seems reasonable to counteract enamel dis-

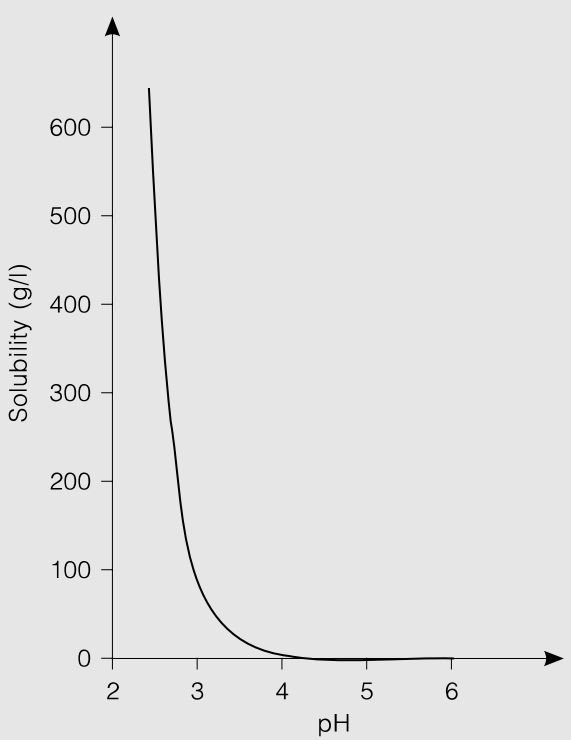

Fig. 2. Apatite solubility as a function of $\mathrm{pH}$ in the range from 7 to 2.4 as calculated by a previously published program [Larsen, 1986] under conditions as those in figure 1. A tremendous increase in apatite solubility in the lower $\mathrm{pH}$ range can be seen. The horizontal line indicating calcium phosphate levels in saliva coincides with the abscissa and can therefore not be distinguished.

solution by addition of calcium phosphate to a drink with a $\mathrm{pH}$ as low as 4 . The solubility of apatite increases from $75 \mathrm{~g} / \mathrm{l}$ at $\mathrm{pH} 3$ to $400 \mathrm{~g} / \mathrm{l}$ at $\mathrm{pH} 2.5$. In comparison, the entire permanent dentition weighs less than $50 \mathrm{~g}$ [Bolk, 1925]. However, this does not mean that a dentition can be dissolved in 1 liter of a $\mathrm{pH} 3$ juice because during the dissolution of dental apatite, $\mathrm{pH}$ shifts to higher values as a result of the dissolution of the apatite [Larsen et al., 1993]. Further, the above calculation is based on equilibrium conditions which do never occur in the oral cavity: most of the drinks wash quickly through the mouth without even being in contact with the teeth.

Apart from its $\mathrm{pH}$, the ability of an acidic solution to dissolve enamel apatite depends on its ability to keep $\mathrm{pH}$ unaffected by the dissolution of apatite and dilution with saliva, i.e. its buffering effect. The higher the buffering effect or concentration of acids in the drink, the more apatite will be dissolved before neutral $\mathrm{pH}$ is approached and the dissolution brought to an end. Therefore, it seems likely that an acidic solution with a high buffering effect in the low $\mathrm{pH}$ 
Table 1. Concentrations of some inorganic ions and $\mathrm{pH}$ in soft drinks, mineral waters and orange juices

\begin{tabular}{|c|c|c|c|c|c|c|}
\hline & \multirow[t]{2}{*}{$\mathrm{pH}$} & \multicolumn{2}{|c|}{$\begin{array}{l}\text { Buffer effect }{ }^{1} \\
\mathrm{mmol} / 1\end{array}$} & \multirow{2}{*}{$\begin{array}{l}\text { Calcium } \\
\text { concentration } \\
\mathrm{mmol} / \mathrm{l}\end{array}$} & \multirow{2}{*}{$\begin{array}{l}\text { Phosphate } \\
\text { concentration } \\
\text { mmol/l }\end{array}$} & \multirow{2}{*}{$\begin{array}{l}\text { Fluoride } \\
\text { concentration } \\
\text { ppm }\end{array}$} \\
\hline & & $\rightarrow \mathrm{pH} 5.5$ & $\rightarrow \mathrm{pH} 7.0$ & & & \\
\hline Schweppes Indian Tonic & 2.48 & 47 & 68 & 0.43 & 0 & 0.41 \\
\hline Schweppes Dry Grape & 2.76 & 47 & 66 & 0.58 & 0.18 & 0.33 \\
\hline Fanta Orange & 2.86 & 32 & 51 & 0.38 & 0.13 & 0.20 \\
\hline Sprite Light & 2.98 & 16 & 31 & 0.36 & 0 & 0.58 \\
\hline Coca Cola & 2.40 & 9 & 25 & 0.26 & 5.47 & 0.20 \\
\hline Pepsi Cola & 2.53 & 8 & 18 & 0.09 & 5.46 & 0.45 \\
\hline $7 \mathrm{Up}$ & 3.20 & 15 & 33 & 0.19 & 0 & 0.58 \\
\hline Orange Juice MD & 3.84 & 78 & 107 & 2.97 & 3.55 & 0.80 \\
\hline Orange Juice MD/calcium & 4.03 & 78 & 109 & 42.90 & 31.20 & 0.09 \\
\hline Carlsberg Kurvand/citrus-lime & 4.02 & 5 & 17 & 1.18 & 0 & 0.06 \\
\hline Carlsberg Kurvand & 4.59 & 2 & 17 & 1.15 & 0 & 0.09 \\
\hline Tuborg Blue/citrus-lime & 5.42 & 0 & 11 & 0.35 & 0 & 0.20 \\
\hline Tuborg Blue Special & 5.44 & 0 & 21 & 0.38 & 0 & 0.35 \\
\hline Aqua Minerale/citrus-lime & 5.01 & 0 & 11 & 0.34 & 0 & 0.52 \\
\hline Aqua Minerale & 5.11 & 0 & 11 & 0.33 & 0 & 0.55 \\
\hline Apollinaris/citrus-lime & 4.44 & 0 & 5 & 0.42 & 0.01 & 0.17 \\
\hline Maarum & 5.38 & 0 & 20 & 0.90 & 0 & 1.78 \\
\hline Apollinaris & 4.88 & 0 & 10 & 3.03 & 0.01 & 0.41 \\
\hline Distilled water & 5.60 & & & & & \\
\hline
\end{tabular}

1 Buffer effect defined as the amount of alkali needed to bring $\mathrm{pH}$ to 5.5 or 7.0 (in $\mathrm{mmol} / \mathrm{l}$ ).

range may be more harmful to enamel compared to a solution with the same buffering effect, however, in the higher $\mathrm{pH}$ range. To which extent the value of $\mathrm{pH}$ or the buffering effect is the most important is unclear.

An additional factor of significance in erosion is the concentration of calcium, phosphate and fluoride in the acidic drink. Generally, the concentrations of these ions are low and far from sufficient for saturation of the drink, but modification of the drink by supplementation has been shown to significantly counteract dental erosion [for review see Grenby, 1996a]. Because the solubility of enamel apatite increases so steeply (fig. 1,2) only drinks with $\mathrm{pH}$ above 3.5 may realistically benefit from calcium phosphate supplementation in counteracting enamel dissolution.

The aim of the present study was to examine the $\mathrm{pH}$ of various soft drinks and juices available on the Danish market, their buffering effect with emphasis on the $\mathrm{pH}$ range in which the buffer is efficient, and their contents of calcium, phosphate and fluoride, for a comparison with their ability to dissolve dental enamel in vitro.

Enamel Erosion by Soft Drinks and Orange Juice

\section{Materials and Methods}

Eighteen commonly available soft drinks and juices on the Danish market were chosen for the study (table 1). Each drink was by chemical analysis characterized by its concentration of ions of dental interest by the following methods: calcium by AA spectrophotometry [Willis, 1961], phosphate by color spectroscopy [Chen et al., 1956], and fluoride by electrode (Orion $\left.{ }^{\circledR}\right)$; $\mathrm{pH}$ was determined by glass electrode immediately after opening the bottle and subsequently in a poured 10-ml volume of the drink. The buffering effect in $3 \mathrm{ml}$ of each drink was determined by monitoring $\mathrm{pH}$ after serial additions of $0.025 \mathrm{ml} 0.2 \mathrm{~mol} / \mathrm{l} \mathrm{NaOH}$. For comparative purposes, the amount of $\mathrm{NaOH}$ necessary to change the $\mathrm{pH}$ of 1 liter of the actual drink to $\mathrm{pH} 4.0,5.0,5.5$ and to 7.0 was calculated.

The erosive potential of the drinks and distilled water was studied in a total of 54 freshly extracted human premolars and molars which prior to experimentation were covered with nail varnish except for $3 \times 4-\mathrm{mm}$ windows left for exposure. During the exposure to the drinks the teeth were hung onto closed 2-ml, test tubes serving as floating buoys. Bottles containing 1.5 liters of soft drink were cautiously opened, a few milliliters of the content removed for analysis, and a tooth hanging under its test tube was set to float with the tooth submersed in the drink before the bottles were closed again. Care was taken to avoid loss of carbon dioxide during opening and the subsequent exposure period. All bottles were continuously gently agitated on a table for $24 \mathrm{~h}$ or 1 week before discontinuation of the exposure.

After the exposure, the teeth were sectioned longitudinally and ground to a thickness of approximately $100 \mu \mathrm{m}$. The depth of the ero-

Caries Res 1999;33:81-87 


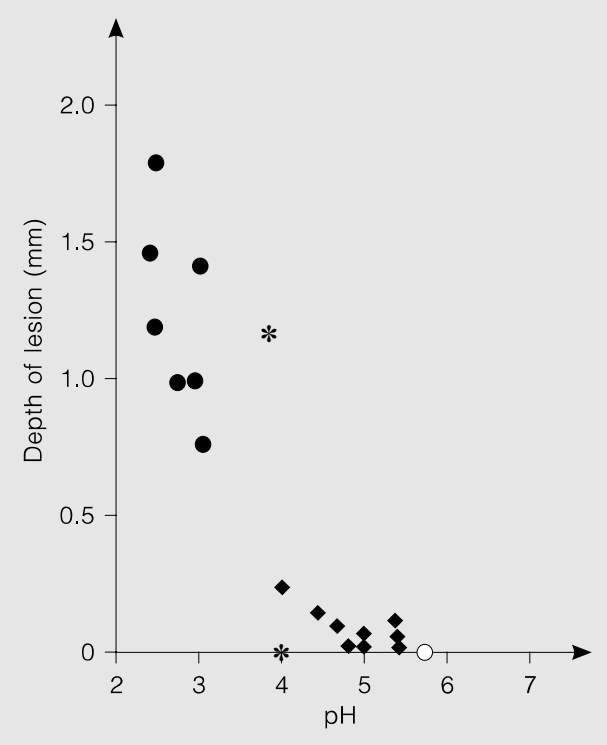

Fig. 3. Depths of artificial erosions in enamel after exposure to soft drinks $(\bullet)$, mineral waters $(\bullet)$, orange juices with and without calcium phosphate supplementation $(*)$ and distilled water $(\bigcirc)$ for 1 week as a function of $\mathrm{pH}$ of the drink. Note that the calcium phosphate-supplemented orange juice did not erode the enamel. If the orange juices are disregarded, the series of points tends to indicate a curved line of a shape similar to those in figures 1 and 2 .

sions was assessed using a Quantimet 550+ (Leica). For each lesion the greatest distance from the eroded surface perpendicular to the redrawn original anatomical enamel surface was recorded as the depth of the erosion. The mineral distribution of the eroded teeth was examined in microradiographs produced by a Machlett X-ray tube operated at $20 \mathrm{~mA}$ and $20 \mathrm{mV}$.

All experiments and analyses were duplicated in two separate runs. For calculation of enamel solubilities, a previously published computer program [Larsen, 1986] was used. The solubility product for hydroxyapatite was $10^{-58.5}$ [McDowell et al., 1977] and that for fluorapatite 10-59.6 [McCann, 1968]. A regression analysis was made according to Armitage [1977]. The use of human teeth for this experiment was approved by an ethical committee.

\section{Results}

\section{Chemical Analysis}

The soft drinks and juices were found to fall into three different categories (table 1): (a) carbonated lemonade-like soft drinks with carbohydrates (Schweppes, Coca-Cola, Pepsi), (b) orange juices, and (c) mineral water-like drinks without sugar. For an overall comparison, the lemonade-

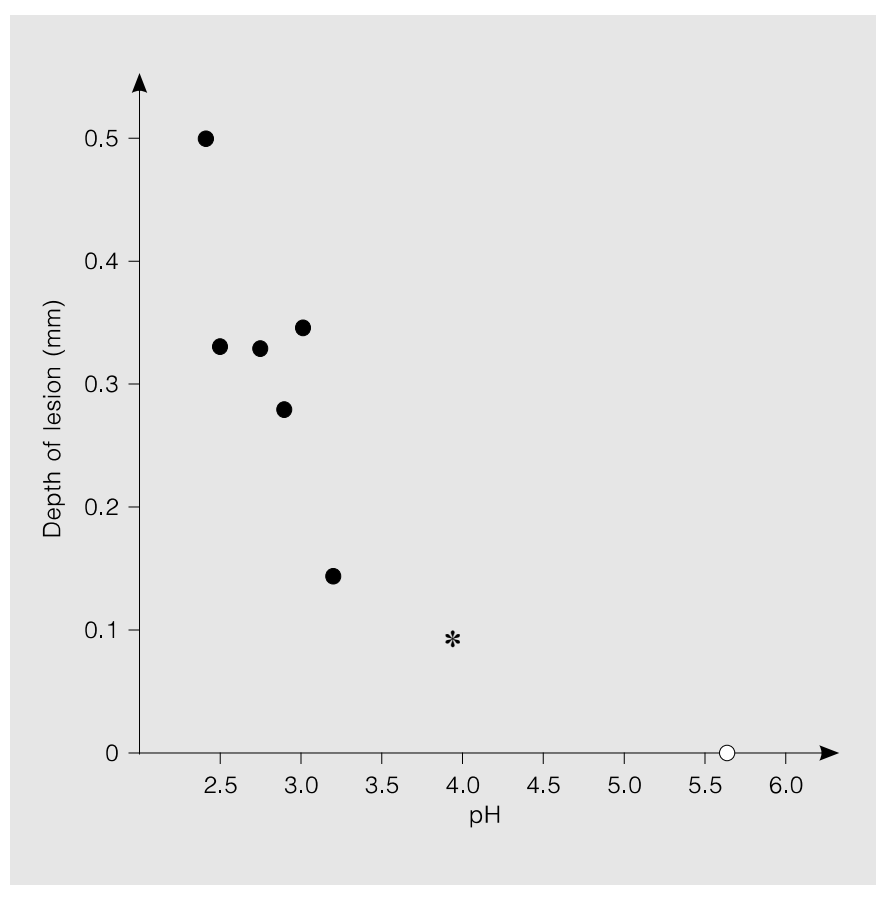

Fig. 4. Depths of artificial erosions in enamel after exposure to lemonade-like carbonated soft drinks $(\bullet)$, orange juice without calcium phosphate supplementation $(*)$ and distilled water $(O)$ for $24 \mathrm{~h}$ as a function of $\mathrm{pH}$ of the drink.

like soft drinks had a low $\mathrm{pH}$ and at least some of them a considerable buffering effect. The $\mathrm{pH}$ of the orange juices ranged around 4 and exhibited a high buffering effect, whilst the $\mathrm{pH}$ of the mineral water-type drinks varied around 5 and above and their buffering was generally weak.

The buffering effect of the two types of juice (orange juice with or without calcium phosphate complementation, respectively) did not differ significantly, despite the fact that the addition of phosphate in concentrations of $28 \mathrm{mmol} / \mathrm{l}$ represents a buffering effect of approximately $10-15 \mathrm{mmol} / \mathrm{l}$ in the $\mathrm{pH}$ range $6-7$. The calcium and phosphate concentrations in the orange juice supplemented with minerals ranged around 43 and $31 \mathrm{mmol} / \mathrm{l}$, which by calculation corresponds to the solubility of apatite in distilled water at $\mathrm{pH} 4$.

In contrast to the juices, when the carbonated drinks were poured some carbon dioxide escaped and $\mathrm{pH}$ rose somewhat. The $\mathrm{pH}$ rise was considerable in the mineral waters and less in the lemonade-type carbonated drinks. The $\mathrm{pH}$ of the lemonade-type of soft drinks with sugar was lower than that of the juices, but the buffering effect was con- 
siderably smaller, with Schweppes drinks at the upper end and the colas at the lower end of the range. The colas contained around $5.7 \mathrm{mmol} / \mathrm{l}$ phosphate in contrast to the other drinks. The $\mathrm{pH}$ of the mineral water-type of drinks was comparatively high and the buffering effect of this kind of drink was low, irrespective of the addition of citrus and lime. In this category $\mathrm{pH}$ rose almost half a unit upon pouring.

The fluoride concentration was low in all drinks, except for the Maarum mineral water in which $1.8 \mathrm{ppm}$ fluoride was found.

\section{Histologic Examination of Exposed Teeth}

From figures 1 and 2 it appears that 1.5 liters of distilled water at $\mathrm{pH} 7$ can dissolve $0.008 \mathrm{~g}$ of enamel, at $\mathrm{pH} 5$ around $0.5 \mathrm{~g}$, at $\mathrm{pH} 4$ around $5 \mathrm{~g}$, and at $\mathrm{pH} 3$ approximately $85 \mathrm{~g}$. In the actual experiments, only small amounts of enamel and dentin were dissolved: An erosive effect of the mineral water-type of drinks could be difficult to distinguish directly. However, the lesions were clearly identified and measured in the microradiograms. In contrast to the mineral waters, the lemonade-type of soft drinks caused a considerable erosion of the enamel with some of the lesions extending to the dentin. As the organic material of the dentin appeared to protect the underlying mineral and thus to slow down further dissolution, lesions deeper than $2 \mathrm{~mm}$ should be evaluated cautiously as they might have been deeper had the enamel been thicker. A plot of the depths of the lesions induced by exposure for 7 days to the drinks in seen in figure 3: The lemonade-like carbonated soft drinks with $\mathrm{pH}$ below $\mathrm{pH} 3.3$ induced the deeper lesions, whilst the mineral-like waters affected the enamel much less.

When the lesion reached the dentin the rate of demineralization was reduced and the depth determination would therefore be inaccurate. Therefore, a second experiment on the most erosive drinks, the carbonated soft drinks and the orange juice, was made by inducing erosions for a shorter period of $24 \mathrm{~h}$. The examination of the teeth exposed for only $24 \mathrm{~h}$ to the drink showed that, in principle, the lower $\mathrm{pH}$ the deeper was the lesion (fig. 4).

The orange juice that did not contain added calcium and phosphate caused a deep lesion in enamel in contrast to the juice that contained the two ions. Calculation showed that given a pH of 4.03 and concentrations of calcium $43 \mathrm{mmol} / \mathrm{l}$, phosphate $31 \mathrm{mmol} / 1$ and fluoride $0.09 \mathrm{ppm}$, then the ion products in distilled water would be $10^{-53.9}$ for fluorapatite and that of hydroxyapatite $10^{-58.4}$, i.e. a supersaturation with respect to fluorapatite and saturation with respect to hydroxyapatite. Thus, the addition of calcium and phosphate in amounts corresponding to the actual enamel solubility
Table 2. Regression analysis of logarithms of depth of erosion as a function of $\mathrm{pH}$ of the soft drinks and the mineral waters (for details, see text)

\begin{tabular}{llll}
\hline $\mathrm{SSD}_{\text {regression }}$ & 7.5190 & DF 1 & F 91.8103 \\
$\mathrm{SSD}_{\text {around }}$ & 1.0647 & DF 13 & \\
$\mathrm{SSD}_{\text {total }}$ & 8.5837 & DF 14 &
\end{tabular}

Equation $\mathrm{Y}=1.813-0.633 \mathrm{X}$

Correlation coefficient $r=0.936$

was close to establish saturation with respect to hydroxyapatite and, as observed by experimentation, prevented the enamel from dissolving.

\section{Comparisons of Chemical Composition and in vitro \\ Enamel Dissolution}

Overall, figure 3 demonstrates that the erosive effect of drinks above $\mathrm{pH} 4.2$ is limited. At $\mathrm{pH} 4$ and below, the depth of the erosion was found to increase steeply and parallel with the increase in apatite solubility in the low $\mathrm{pH}$ range (fig. 1, 2). Apart from the juices, no particular measurable effect on lesion depth could be attributed neither to the buffering effect of the drinks nor to the content of calcium, phosphate or fluoride. Yet, the Maarum mineral water with $1.8 \mathrm{ppm}$ fluoride did not cause any observable erosion, in contrast to the two Tuborg Blue waters at the same $\mathrm{pH}$ and with only $0.2-0.3 \mathrm{ppm}$ fluoride.

\section{Statistical Results}

From figure 3 it is seen that the depths of the erosions as induced by the drinks decrease logarithmically with $\mathrm{pH}$. Therefore, a regression of the logarithms of the depths on $\mathrm{pH}$ was made (table 2). Due to their special character the juices, with or without added calcium phosphate, were not included in the regression. The Maarum mineral water could not enter the regression as it did not cause any observable erosion. The regression confirmed the close relation between the depth of erosion and the $\mathrm{pH}$ of a drink, $r=0.936$.

\section{Discussion}

No generally accepted golden standard for in vitro development of erosions has been developed [Grenby, 1996b]. In the present study erosions were induced in 1.5 liters of acidic drinks under continuous agitation during 1 week. It must be realized that this exposure was extremely intensive and far from that of real life. The high intensity of 
the exposure was deliberately chosen because buffer effects are more likely to show under prolonged exposure. Furthermore, also drinks with less erosive capabilities may give evidence of erosion under such conditions.

It should be noted that the curves in figures 1 and 2 are derived from an apatite solubility product of $10^{-58.5}$ [McDowell et al., 1977] and is as such theoretical. Below pH 4 it is not possible to verify the curve experimentally because a competing precipitation of brushite masks the results. The reason for that is that the solubility of apatite increases more than that of brushite below pH 4 [Larsen, 1986; Larsen and Jensen, 1989]. Therefore, at e.g. pH 3, as apatite dissolves, a competing precipitation of brushite will prevent saturation of the solution and thus maintain a continuous dissolution of enamel apatite for almost as long as $\mathrm{pH}$ is that low. In conclusion, the theoretical curves cannot be verified experimentally and secondly, if brought to the end the dissolution of apatite might be higher than the curves indicate.

Comparisons of the curves in figures 1 and 2 and the plots in figures 3 and 4 showed that - apart from the juices - the depth of the lesions was a direct function of the enamel apatite solubility at the $\mathrm{pH}$ of the drink, a result comparable to that of Rytömaa et al. [1988]. A characteristic of the curves is their logarithmic nature. Therefore, when regressions are made it seems sensible to use logarithmic plots in order to obtain a good fit for straight line regression (table 2).

The $0.1 \mathrm{mmol} / \mathrm{l}$ calcium and $5.5 \mathrm{mmol} / \mathrm{l}$ phosphate of the colas (table 1) could be supposed to prevent some of the dissolution of enamel. However, at their $\mathrm{pH}$ around 2.5 the solubility of apatite in distilled water ranges around $500 \mathrm{~g}$ apatite per liter (fig. 1), corresponding to $1,000 \mathrm{mmol} / \mathrm{l}$ apatite or $5,000 \mathrm{mmol} / \mathrm{l}$ calcium and $3,000 \mathrm{mmol} / \mathrm{l}$ phosphate per liter. In this context, the $5.5 \mathrm{mmol} / \mathrm{l}$ phosphate in the colas cannot be expected to have a noticeable inhibitory effect on erosion. Further, we observed that the colas dissolved neither more nor less apatite than their $\mathrm{pH}$ suggested.

The calcium and phosphate added to the orange juice had a strong preventive effect on erosion. This particular juice has recently been launched as a 'functional food' intended to counteract osteoporosis. The concentrations of calcium and phosphate in the juice are similar to those in cow's milk products. In the present study the added calcium and phosphate appear to be able to prevent the erosion of the juice itself.

The rather low concentrations of fluoride in the drinks did not affect the depth of the lesions. In the literature, the effect of fluoride has been studied under various conditions with conflicting results [Holloway et al., 1958; Meurman and ten Cate, 1996; Sorvari et al., 1994; Spencer and Ellis,
1950]. Because fluoride is supposed to act in concert with the other ions of the apatite lattice (calcium and phosphate) and in concentrations that saturate the solution with respect to fluorapatite [Larsen et al., 1976], it does not seem likely that fluoride alone has the ability to suppress erosion. However, more work is needed to clarify this problem. For the present study it is concluded that none of the inorganic ions in the drinks had any observable effect on the erosive capabilities, except for the high amounts of calcium phosphate added to the orange juice.

The drinks could be subdivided into three groups according to their buffering effect with the orange juices showing high buffer effects, with the lemonade-like soft drinks as a medium group, and the mineral waters almost without any buffers. It seems likely that the high buffering effect of the juice caused the juice to create a deep erosion in the enamel corresponding to what a drink of one $\mathrm{pH}$ unit lower would have caused. Part of the erosive potential of the juice could probably also be ascribed to its content of organic acids forming organo-calcium complexes which will increase the solubility of enamel apatite beyond what the curves in figures 1 and 2 suggest. For the lemonade-like drinks the buffering effect varied considerably with Schweppes tonic waters in the upper range. A closer examination of the data in the plot figures 3 and 4 shows that the high buffering effect of these tonics did not lead to a deeper erosion than judged from their $\mathrm{pH}$. On the other hand, a comparison of the buffering effect of the tonics with that of juice, as seen in table 1, suggests that an effect might exist.

In conclusion, the present work has shown that mineral waters erode enamel only to a limited extent in contrast to lemonade-like soft drinks and orange juice. Except for the orange juice, the erosive capability of the drinks increased logarithmically inversely with the $\mathrm{pH}$ of the drink and parallel with the solubility of apatite. Further, apart from the orange juice, no effect was observed, neither of calcium, phosphate, and fluoride in the drink nor of their buffering effect. For the orange juice, the very high buffering effect and a very high content of calcium and phosphate in the modified juice affected the erosion significantly. 


\section{References}

Armitage P: Statistical Methods in Medical Research. Oxford, Blackwell, 1977.

Bolk L: Das Gewicht der Zähne. Anat Anz 1925; 59:572-574.

Chen PS, Toribara TY, Warner H: Microdetermination of phosphorus. Anal Chem 1956;28:17561758

Grenby TH: Lessening dental erosive potential by product modification. Eur J Oral Sci 1996a; 104:221-228.

Grenby TH: Methods of assessing erosion and erosive potential. Eur J Oral Sci 1996b;104:207214.

Holloway PJ, Mellanby M, Stewart RJC: Fruit drinks and tooth erosion. Br Dent J 1958;104: 305-309.

Imfeld T: Dental erosion: Definition, classification, and links. Eur J Oral Sci 1996;104:151155.

Larsen MJ: Dissolution of enamel. Scand J Dent Res 1973;81:518-522.

Larsen MJ: Degrees of saturation with respect to apatites in fruit juices and acidic drinks. Scand J Dent Res 1975;83:13-17.

Larsen MJ: An investigation of the theoretical background for the stability of the calcium phosphate salts and their mutual conversion in aqueous solutions at $\mathrm{pH} 5-10$. Arch Oral Biol 1986;31:757-761.
Larsen MJ, V d Fehr FR, Birkeland JM: Effect of fluoride on the saturation of an acetate buffer with respect to hydroxyapatite. Arch Oral Biol 1976;21:723-728.

Larsen MJ, Jensen SJ: Stability and mutual conversion of enamel apatite and brushite at $20^{\circ} \mathrm{C}$ as a function of $\mathrm{pH}$ of the aqueous phase. Arch Oral Biol 1989;34:963-968.

Larsen MJ, Pearce EIF, Jensen SJ: Notes on the dissolution of human dental enamel in dilute acid solutions at high solid/solution ratio. Caries Res 1993;27:87-95.

Lussi A, Jäggi T, Schärer S: The influence of different factors on in vitro enamel erosion Caries Res 1993;7:387-393.

McCann HG: The solubility of fluorapatite and its relationship to that of calcium fluoride. Arch Oral Biol 1968;13:987-1001.

McDowell H, Gregory TM, Brown WE: Solubility of $\mathrm{Ca}_{5}\left((\mathrm{PO})_{4}\right)_{3} \mathrm{OH}$ in the system $\mathrm{Ca}(\mathrm{OH})_{2}$ $\mathrm{H}_{3} \mathrm{PO}_{4}-\mathrm{H}_{2} \mathrm{O}$ at $5,15,25$, and $35.5^{\circ} \mathrm{C}$. J Res Natn Bur Stand 1977;81A:773-782.

Meurman JH, ten Cate JM: Pathogenesis and modifying factors of dental erosion. Eur J Oral Sci 1996;104:199-206.

Meurman JH, Härkönen M, Näveri H, Koskinen J, Torkko H, Rytömaa I, Järvinen V, Turunen R: Experimental sports drinks with minimal dental erosion effect. Scand J Dent Res 1990;98 $120-128$
Meurman JH, Rytömaa I, Kari K, Mutomaa H: Salivary $\mathrm{pH}$ and glucose after consuming various beverages, including sugar-containing drinks. Caries Res 1987;21:353-359.

Nunn JH: Prevalence of dental erosion and the implications for oral health. Eur J Oral Sci 1996;104:156-161.

Rytömaa I, Meurman JH, Koskinen J, Laakso T, Gharazi L, Turunen R: In vitro erosion of bovine enamel caused by acidic drinks and other foodstuffs. Scand J Dent Res 1988;96: 324-333.

Sorvari R, Meurman JH, Alakuijala P, Frank RM: Effect of fluoride varnish and solution on enamel erosion in vitro. Caries Res 1994;28: 227-232.

Spencer AJ, Ellis LM: The effect of fluoride and grapefruit on the etching of teeth. J Nutr 1950; 43:107-115.

Willis JB: Determination of calcium and magnesium in urine by atomic absorption spectroscopy. Anal Chem 1961;33:556-559.

Zero DT: Etiology of dental erosion - extrinsic factors. Eur J Oral Sci 1996;104:162-177. 